\title{
Mediterranean clonal selections evaluated for modern hedgerow olive oil production in Spain
}

by Joan Tous, Agusti Romero, Juan Francisco Hermoso and Antonia Ninot

\section{Traditional olive oil production is} limited by its high cost, mainly due to labor expenses for harvesting and pruning. A new olive planting system based on hedgerows and harvesting machines could decrease production costs while maintaining high quality. To improve the efficiency of the continuous-straddle mechanical harvesters, vigor must be managed to limit tree size. However, few cultivars are adapted to this system. Selections from three cultivars are typically used in these super-highdensity orchards. We field-tested 'Arbequina i-18', 'Arbosana i-43' and 'Koroneiki i-38' in an irrigated, super-high-density planting system in Catalonia (northeast Spain). We present a review of 6 years of horticultural data and summarize sensory characteristics and other properties of the resulting olive oils.

T he olive tree, olive fruit and olive oil have been at the core of Mediterranean agriculture and trade since early cultivation times, providing sustenance to various cultures and civilizations of the Mediterranean Basin. Over the last few decades, olive (Olea europaea) cultivation has undergone important technological changes, which have involved a reduction in the number of olive oil varieties used, and an increase in the density of new plantations that is linked to improvements in harvesting machinery and irrigation systems.

In the early 1990s, a new design and management strategy for olive orchards, the super-high-density hedgerow system, appeared in Catalonia (northeast Spain). Later it was introduced into other Spanish regions and

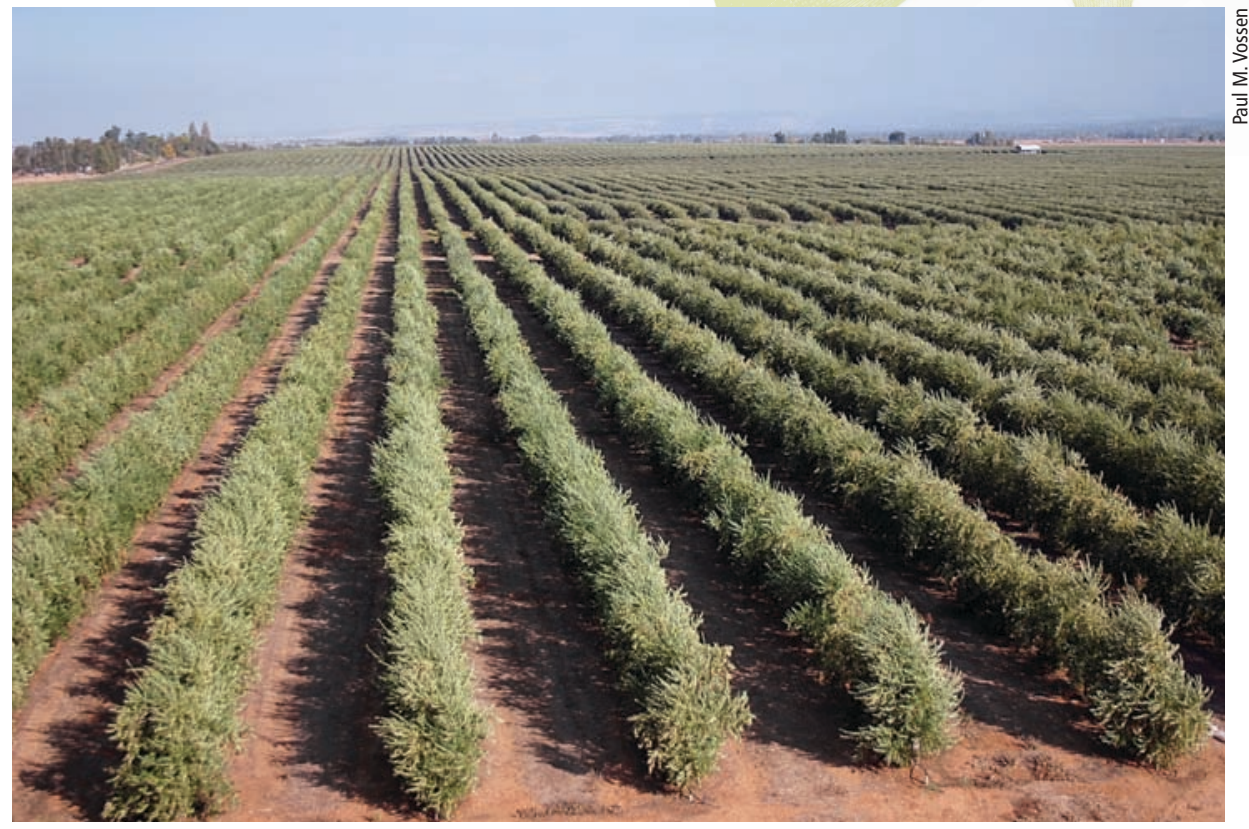

Olive trees have been cultivated for centuries in Mediterranean climates, including California's Central Valley (shown). New super-high-density hedgerow systems allow for mechanical harvesting, greatly reducing labor costs.

other countries. Clonal selections of local varieties were planted in new olive orchards with tree densities ranging from 600 to 1,000 trees per acre $(1,500$ to 2,500 per hectare) to test the suitability of the plants to mechanization and the production of high-quality, extra-virgin olive oil. Traditional olive orchards have 80 to 200 trees per acre ( 200 to 500 per hectare).

Just a few olive varieties have been compared for their adaptability to high-density plantings and continuous mechanical harvest. Our program at the Institut de Recerca i Tecnologia Agroalimentaria (IRTA) screened three old Mediterranean olive

Editor's note: More than 12,000 acres of olives have been planted in California using the super-high-density system. Research in California is inconclusive about the long-term viability of super-high-density olive culture under California growing conditions; further field studies based in the state can address these questions. varieties - 'Arbequina' and 'Arbosana' from Catalonia and 'Koroneiki' from Crete (Greece) - to identify those with outstanding characteristics such as compact growth habits, low-medium vigor, early maturity and excellent oil quality (Tous et al. 2003). Agronomical evaluations in Spain and other countries have shown that these IRTA clones are precocious (bearing their first crop at an earlier age than standard cultivars), achieve higher yields earlier after planting and produce extra-virgin oil of excellent quality.

\section{California olive orchards}

Olives were introduced in California by the Catalan Franciscan fathers, who planted olive trees in gardens adjacent to their missions. Their olives and oil were appreciated not only as food but also as an element in liturgical celebrations.

Today, the predominant table olive industry in California is supported by classic cultivars introduced for their suitability to traditional and intensive table olive orchard systems (Tous and Ferguson 1997; Vossen 2007). In California, the industry generally plants 
five cultivars (Mission, Manzanillo, Sevillano, Ascolano and Barouni) to produce black-ripe olives (Connell 2005). 'Mission' trees were likely introduced to California during Franciscan times, via Mexico in 1769 (Sutter 2005).

Olive planting for oil production, by contrast, has grown from negligible acreage in 1996 to approximately 16,000 acres $(6,400$ hectares) by 2008 . Most of this acreage, 12,000 acres $(4,800$ hectares), is planted in super-high-density orchards with 560 to 870 trees per acre (1,400 to 2,175 per hectare) (UC Davis Olive Center 2009).

Most high-density California olive plantings are three releases of IRTA's clonal plant material from the Mas de Bover research station in Catalonia, Spain, the initial selections from their olive improvement program started in the mid-1980s. The IRTA clonal varieties currently available are 'Arbequina i-18', 'Arbosana i-43' and 'Koroneiki i-38', propagated in California by a few authorized nurseries. The success of these early clonal selections and the superhigh-density system is also evidenced by their early adoption in traditional olive oil-producing countries, such as Spain, Portugal, Tunisia and Morocco, as well as diverse, nontraditional olivegrowing regions that are beginning to produce extra-virgin olive oils of

\begin{tabular}{llll}
\multicolumn{2}{c}{ TABLE 1. Horticultural characteristics of three olive tree clones tested in a super-high-density } \\
planting system in Catalonia, Spain
\end{tabular}

remarkable quality such as California, Chile and Australia.

We describe the performance and limitations of these olive oil clones in comparative field trials performed in an irrigated, super-high-density system in Catalonia, which supports their adoption in modern orchards. We also contribute additional information to help define the suitable orchard design and management of super-high-density plantings in California.

\section{Horticultural characteristics}

The clone 'Arquebina i-18' was obtained in 1997 in a program to identify and select outstanding individuals of 'Arbequina', the most important cultivar in Catalonia $(160,000$ acres $[65,000$ hectares]) from traditional orchards located in the PDOs (protected designations of origin) of Les Garrigues and Siurana in northeast Spain. 'Arbosana i-43' was selected in 1987 from surveys of the 'Arbosana' cultivar in the Alt Penedès region in Catalonia. The clone 'Koroneiki i-38' was selected in 1990 from trees of this Greek variety at the Mas de Bover research station. Morphological descriptions of the tree, leaf, fruit and endocarp for these cultivar clones have been published (Tous et al. 1999; Tous and Romero 2000, 2002).

\section{Crop performance}

The first comparative field trial with these clones in super-high-density hedgerow orchards was planted in
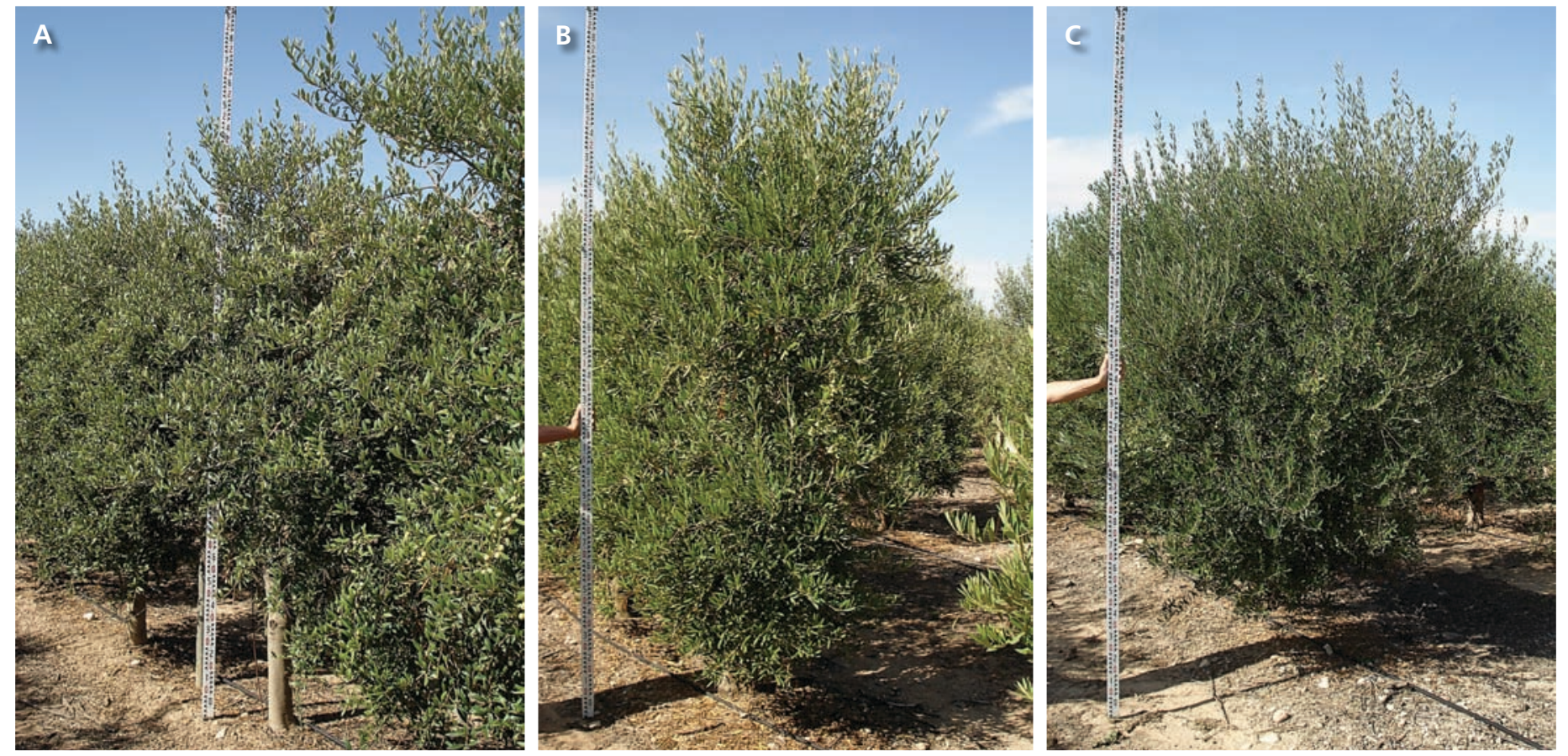

The growth habit of 11-year-old trees is shown for the IRTA clones (A) 'Arbequina i-18' (B) 'Arbosana i-43' and (C) 'Koroneiki i-38', in a hedgerow, super-high-density planting system in 2009, in Spain. 


\section{As the newly planted super-high-density orchards in California enter their optimal olive oil production phase, it will be interesting to compare and follow experiences and observations with other regions.}

Tarragona in 1998 (Tous et al. 2003, 2008) (table 1).

Yields. Differences between varietals in cumulative fruit yield became evident during early years of the trial (table 2). In Tarragona, the highest cumulative yields were measured for 'Arbequina i-18' (31,875 pounds per acre) followed by 'Arbosana i-43' (26,470 pounds per acre) and 'Koroneiki i-38' (22,361 pounds per acre). In a similar trial in Cordoba (Andalusia, southern Spain), 'Arbequina i-18', 'Arbosana i-43' and 'Koroneiki i-38' showed higher mean harvest yields ( 3 to 6 years after planting) than other varieties tested (data not shown) (León et al. 2006); in this southern location 'Koroneiki i-38' was the most precocious (table 2). During the first years of both trials, the influence of environment on precocity and average crops achieved was larger in Cordoba due to the higher vegetative tree growth in this province.

The mean harvest of super-highdensity cultivars in Tarragona was 4,397 pounds per acre (3rd year), 4,205 pounds per acre (4th year; frost on trees affected productivity), 10,344 pounds per acre (5th year) and 7,291 pounds per acre (6th year), all similar to harvests obtained in other high-density orchards in Spain. The high yields observed in early years of the Spanish trials and commercial orchards are not sustainable. Under the favorable growing conditions that foster vigorous tree growth, a reduction in potential production occurs in the 6th to 8 th years, with averages of 7,138 to 8,030 pounds per acre,

\begin{tabular}{|c|c|c|c|c|c|c|}
\hline \multirow[b]{2}{*}{ Year } & \multicolumn{2}{|c|}{ Arbequina i-18 } & \multicolumn{2}{|c|}{ Arbosana i-43 } & \multicolumn{2}{|c|}{ Koroneiki i-38 } \\
\hline & Tarragona & Cordoba & Tarragona & Cordoba & Tarragona & Cordoba \\
\hline & . & $\ldots \ldots \ldots$ & $\cdots \cdot \mid b / c$ & $e^{*}$. & $\cdots$ & ..... \\
\hline Second & 1,102 & 0 & 803 & 273 & 0 & 3,213 \\
\hline Third & 6,002 & 13,203 & 4,771 & 15,305 & 2,416 & 18,502 \\
\hline Fourth $†$ & 4,428 & 12,527 & 2,833 & 7,990 & 5,356 & 5,440 \\
\hline Fifth & 12,038 & 17,957 & 12,173 & 17,279 & 6,822 & 11,170 \\
\hline Sixth & 8,305 & 5,519 & 5,890 & 6,583 & 7,678 & 4,027 \\
\hline Average (3th-6th) & 7,693 & 12,302 & 6,537 & 11,790 & 5,568 & 9,786 \\
\hline $\begin{array}{l}\text { Cumulative yield } \\
\text { (Ib/acre) }\end{array}$ & 31,875 & 49,207 & 26,470 & 47,431 & 22,361 & 42,354 \\
\hline
\end{tabular}

TABLE 3. Vegetative and productive characteristics of three olive cultivars growing in a 5-year-old, super-high-density orchard in Catalonia, Spain, 2000-2003 (2nd-5th year after planting)

\begin{tabular}{|c|c|c|c|c|c|}
\hline Cultivar & $\begin{array}{c}\text { Suckers } \\
\text { (4th year) }\end{array}$ & $\begin{array}{c}\text { TCSA* } \\
\text { (5th year) }\end{array}$ & $\begin{array}{c}\text { Canopy volume } \\
\text { (5th year) }\end{array}$ & $\begin{array}{l}\text { Cumulative } \\
\text { yield } \\
\text { (2nd-5th year) }\end{array}$ & Yield efficiency \\
\hline & & $i n^{2} \dagger$ & $\mathrm{ft}^{3} / \mathrm{acre}$ & Ib/acre & $\sum l b / f t^{3} \ddagger$ \\
\hline Arbequina i-18 & $0.4 c \S$ & $5.54 c$ & $192.389 \mathrm{ab}$ & $23.539 a$ & $0.12 a$ \\
\hline Arbosana i-43 & $1.4 \mathrm{~b}$ & $5.85 b c$ & $168.795 b$ & $21.330 a b$ & $0.12 a$ \\
\hline Koroneiki i-38 & $5.2 a$ & $7.67 a$ & 189.674ab & $14.594 c$ & $0.07 b c$ \\
\hline \multicolumn{6}{|c|}{$\begin{array}{l}\text { * Trunk cross-sectional area. } \\
+1 \text { inch }{ }^{2}=6.4516 \mathrm{~cm}^{2} ; 1 \mathrm{ft}^{3} / \mathrm{acre}=0.0700 \mathrm{~m}^{3} / \mathrm{ha} ; 1 \mathrm{lb} / \mathrm{acre}=1.1209 \mathrm{~kg} / \mathrm{ha} ; 1 \mathrm{lb} / \mathrm{ft}^{3}=16.0185 \mathrm{~kg} / \mathrm{m}^{3} \text {. } \\
\text { ₹ Sum of first yields ( } 2 \mathrm{nd} \text { to } 5 \text { th year) per cubic foot of canopy volume at } 5 \text { th year }(2003) \text {. } \\
\text { § Mean separation within columns by Duncan's multiple range test, } P<0.05 \text {. }\end{array}$} \\
\hline
\end{tabular}

usually due to shade and limited ventilation in the tree canopies (Tous et al. 2010). The yields of 7- to 10-year-old orchards are more variable and depend on management of the canopy volume, which should not exceed 143,000 to 171,500 cubic feet per acre to facilitate movement of the over-the-row harvesters.

Vigor. We observed the lowest tree vigor (trunk cross-section, canopy volume and sucker emission) in 'Arbosana i-43' and 'Arbequina i-18' (table 3). 'Koroneiki i-38' is notorious for being more vigorous and producing more suckers than the other cultivars. The yield efficiency of each varietal clone was measured to determine the balance between productive and vegetative activity during the early bearing phase. The highest index scores were observed in 'Arbequina i-18' and 'Arbosana i-43' ( 0.12 pound per cubic foot), followed by 'Koroneiki i-38' (0.07 pound per cubic foot). 'Koroneiki i-38' showed a higher tendency to vegetative growth, and the crop was irregular among trees during the first years of the trial.

Mechanical harvest. Several intrinsic varietal characteristics, such as growth habit and canopy width, influence the efficiency of fruit removal during mechanical harvest. Our selections display two growth habit categories: semi-erect ('Arbequina i-18') and open canopy ('Arbosana i-43' and 'Koroneiki i-38'). Straddle machines or grape harvesters perform better than trunk shakers for these cultivars. More than $90 \%$ of the fruit was removed in all cultivars, independent of their size, position in the canopy and maturation index. By contrast, the efficiency of trunk-shaking harvesters is clearly influenced by growth habit (Pastor et al. 1998), and yield is improved with an erect or semierect tree shape, large fruits and low fruit removal force.

Disease. 'Arbequina i- 18 ' is more sensitive than the other selections to olive leaf spot (Spilocaea oleagina) when planted in coastal environments and humid valleys. 'Arbequina i-18' is more tolerant than the other two cultivars to frost, while 'Koroneiki i-38' is the most sensitive. 
Harvest time. Gradual fruit ripening and maturation is commonly observed in the three cultivars, although this parameter is highly influenced by tree fruit load and seasonal conditions as well as geographical location. Optimal harvest time is different for each of the cultivars: 'Arbequina i-18' is optimal in Catalonia from mid-November to midDecember, 'Koroneiki i-38' matures in late December and 'Arbosana i-43' in mid-January.

Fruit and oil characteristics. 'Arbequina i-18' produced larger fruits than the other two cultivars (table 4). The pulp/stone ratio was higher for 'Arbosana i-43' and 'Arbequina i-18', followed by 'Koroneiki i-38'. Fruit water content ranged between $56.0 \%$ in 'Koroneiki i-38' and 61.1\% in 'Arbosana i-43'. Oil content expressed as percentage of dry weight was higher in 'Arbequina i-18' (54.4\%), followed by 'Koroneiki i-38' (52.4\%) and 'Arbosana i- $43^{\prime}(50.7 \%)$.

The three clonal selections produced extra-virgin olive oil of excellent quality. The fatty acid composition of 'Arbequina i- 18 ' and 'Arbosana i- $43^{\prime}$ oils was similar (table 5). 'Koroneiki i-38' oil is characterized by a higher content of oleic acid (more than $76 \%$ ) at the expense of palmitic and linoleic acid, which contribute to longer shelf life. 'Arbosana i-43' and 'Koroneiki i-38' oils were consistently richer in polyphenols than 'Arbequina i-18'. When compared at the organoleptic sensory level (fig. 1), 'Arbequina i-18' oil was the most balanced of the three, with a medium fruity intensity, balanced in the palate and an outstanding sweetness. 'Koroneiki i-38' produced the most fruity, green, bitter and pungent oil of

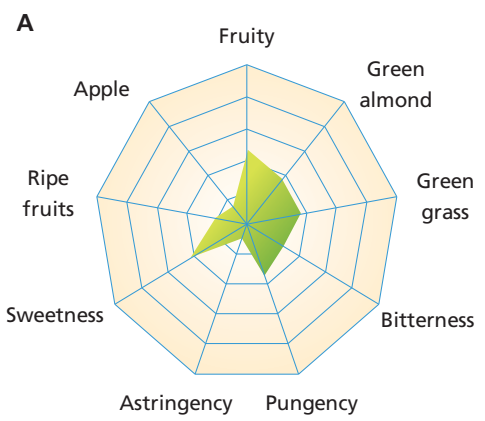

TABLE 4. Fruit characteristics of three IRTA clones tested in an irrigated, super-high-density planting system in Catalonia, Spain, from trees 3 to 7 years old, 2001-2005

\begin{tabular}{lccccc}
\hline \hline \multicolumn{1}{l}{ Cultivar } & Fruit weight & $\begin{array}{c}\text { Pulp/stone } \\
\text { ratio }\end{array}$ & Oil content & Moisture & Oil content \\
\hline Arbequina i-18 & $g$ & & $\%$ fresh weight & $\%$ & $\%$ dry weight \\
Arbosana i-43 & $1.72 \pm 0.18^{*}$ & $4.31 \pm 0.59$ & $21.9 \pm 1.0$ & $60.1 \pm 3.0$ & $54.4 \pm 2.5$ \\
Koroneiki i-38 & $1.59 \pm 0.37$ & $4.69 \pm 0.54$ & $19.8 \pm 0.8$ & $61.1 \pm 2.2$ & $50.7 \pm 2.8$ \\
\hline * Mean values \pm standard error (SE). & $0.90 \pm 0.14$ & $3.44 \pm 0.84$ & $22.9 \pm 0.8$ & $56.0 \pm 2.3$ & $52.4 \pm 3.4$ \\
\hline
\end{tabular}

TABLE 5. Olive oil characteristics* of three IRTA clones tested in an irrigated, super-high-density planting system in Catalonia, Spain, from trees 5 to 6 years old, 2003 and 2004

\begin{tabular}{|c|c|c|c|c|c|c|c|}
\hline Cultivar & $\begin{array}{c}\text { Palmitic } \\
\text { acid, C16:0 }\end{array}$ & $\begin{array}{c}\text { Oleic acid, } \\
\text { C18:1 }\end{array}$ & $\begin{array}{c}\text { Linoleic } \\
\text { acid, C18:2 }\end{array}$ & $\begin{array}{c}\text { Linolenic } \\
\text { acid, C18:3 }\end{array}$ & $\begin{array}{c}\text { Total } \\
\text { polyphenols }\end{array}$ & Bitterness & Oil stability \\
\hline & & 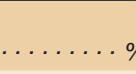 & & & $\begin{array}{c}\text { ppm } \\
\text { cafeic acid }\end{array}$ & $K_{225}$ & hours t \\
\hline Arbequina i-18 & 14.5ał & $69.4 c$ & $11.1 \mathrm{a}$ & $0.72 b$ & $234 b$ & $0.2 \mathrm{a}$ & $9.10 \mathrm{~b}$ \\
\hline Arbosana i-43 & $13.6 a$ & $73.0 \mathrm{~b}$ & $7.9 b$ & $0.9 a$ & $343 a$ & $0.30 a$ & $12.8 \mathrm{ab}$ \\
\hline Koroneiki i-38 & $11.4 b$ & $76.6 a$ & $6.89 c$ & $0.93 a$ & $400 a$ & $0.45 b$ & $15.23 a$ \\
\hline
\end{tabular}

* Oil characteristics: main fatty acid composition (\%), total polyphenols (ppm cafeic acid), bitterness $\left(\mathrm{K}_{225}\right)$ and oil stability. † Oil stability against oxidation, applying Rancimat method (hours at $120^{\circ} \mathrm{C}$ ).

₹ Mean separation within columns by Duncan's multiple range test, $P<0.05$.

the three, and 'Arbosana i-43' oils had an intermediate palate profile. Oil composition and flavor change as the olive fruit develops. The distinctive and contrasting sensory attributes of the extravirgin oils from each varietal allows for unique blends with a wide range of interesting sensory characteristics.

\section{Field observations}

Initial observations from the Mas de Bover cultivar trials and orchard design evaluations, initiated in the 1980s, have been validated by the worldwide adoption of IRTA's clonal selections. The three initial selections described here have been planted in new high-density (121 to 242 trees per acre) and superhigh-density (over 600 trees per acre) olive tree orchards around the world, and most recently California.

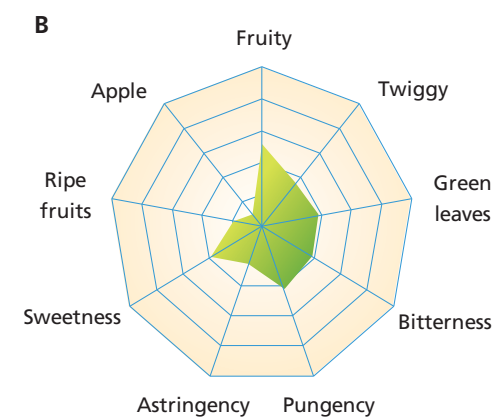

The most consistent plant characteristics and performance, as observed in super-high-density orchards around the world, can be summarized as follows:

'Arbequina i-18'. This highly productive variety is early bearing with little alternating bearing. It is considered frost resistant and adaptable to different climatic and soil conditions, and is adaptable to high-density and superhigh-density hedgerow orchards. Its semi-erect growth habit facilitates its training on a central leader. It produces medium-fruited extra-virgin oil that is balanced in the mouth; the sweet attribute is outstanding and easily appreciated by new consumers. Its commercialization can be monovarietal or blended with other oils.

'Arbosana i-43'. This is an earlybearing cultivar with high productivity.

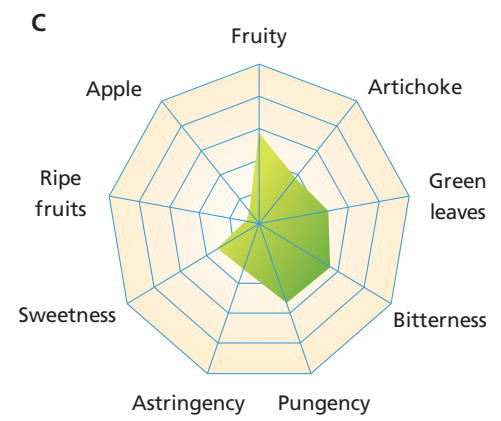

Fig. 1. Sensorial profiles of olive oils from three IRTA clones: (A) 'Arbequina i-18', (B) 'Arbosana i-43' and (C) 'Koroneiki i-38'. The green polygon represents the intensity of each taste attribute scored on a 10-point scale. 

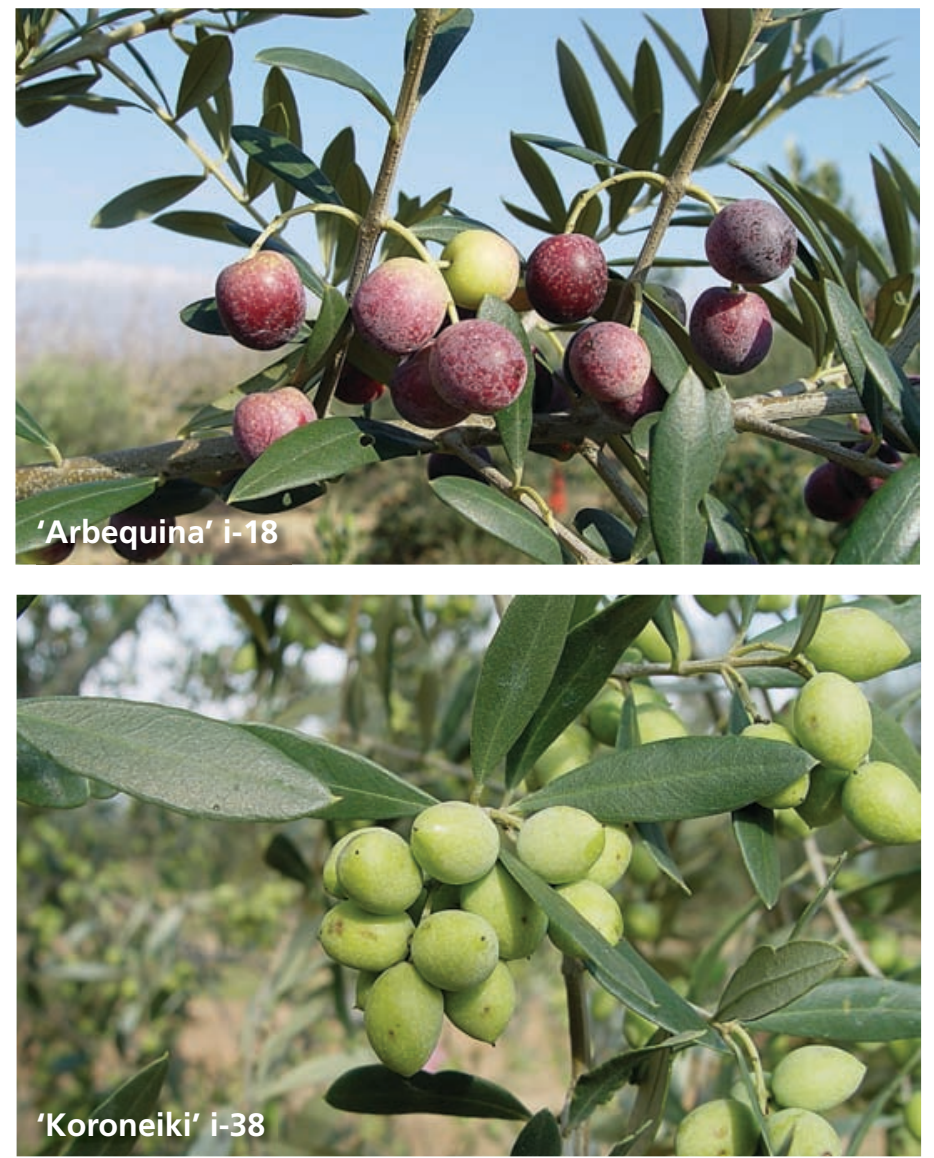

Due to its low vigor, it adapts well to hedgerow systems for olive growing. Sensitive to frost, its fruit is small and ripens several weeks later than 'Arbequina'. It produces intense, greenfruited virgin oil with high levels of bitterness, spiciness and astringency. Due to its higher polyphenol content, it is particularly interesting for blending and to stabilize and prolong the shelf life (time to rancidity) of the milder 'Arbequina' oil.

'Koroneiki i-38'. This is a productive and early-bearing cultivar. It is considered drought resistant but frost sensitive, and well suited to hot growing areas. It is tolerant to olive leaf spot and has very small fruit, which ripen after 'Arbequina' but before 'Arbosana'. It produces quite-stable extra-virgin oils, rich in oleic acid and polyphenols, with intense green color and bitterness, and a long shelf-life.

\section{Olive tree breeding program}

Scientists at IRTA's Mas de Bover research station are evaluating additional clonal materials and old orchards of olive varieties, and prioritizing the search

\section{References}

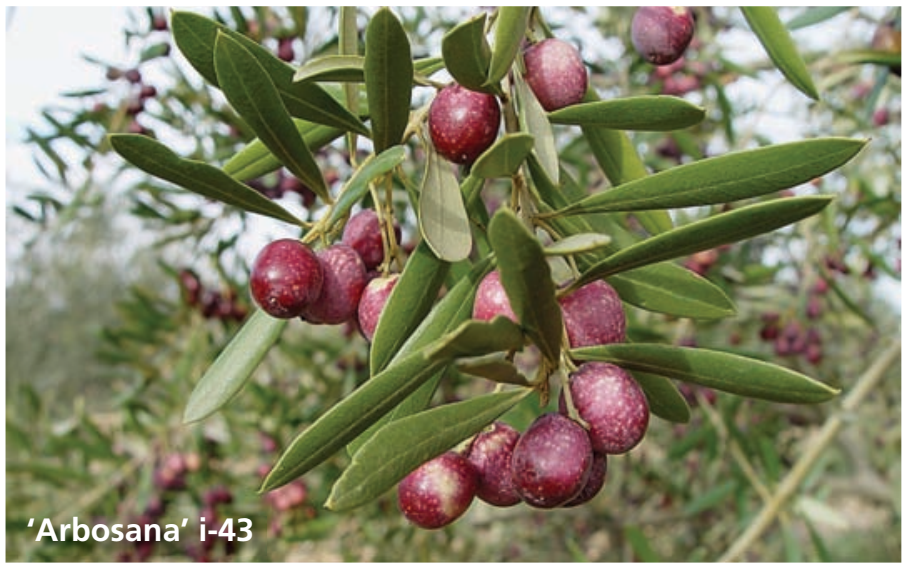

Fruit of three clones used in super-highdensity planting systems. 'Arbequina i-18' and 'Arbosana i-43' are native to Catalonia, Spain, and 'Koroneiki i-38' is native to Greece. sources of novel germplasm to produce olives of improved agronomic performance and desirable olive oil sensory attributes.

As the newly planted super-highdensity orchards in California enter their optimal olive oil production phase, it will be interesting to compare experiences and observations with other regions in terms of economic viability, orchard management and sustainability, natural resource utilization and extra-virgin oil qualities.

for varietal characteristics that can improve productivity, a low vigor/compact growth habit, disease resistance and extra-virgin olive oil with high levels of antioxidants. IRTA recently initiated a project to catalogue a collection of ancient trees (estimated 500 to 700 years old) in local orchards around northeast Spain that contain individual trees of unclear varietal origin, as potential

Connell JH. 2005. History and scope of the olive industry. In: Sibbett GS, Ferguson L (eds.). Olive Production Manual (2nd ed.). UC ANR Pub 3353. Oakland CA. p 1-10.

León L, de la Rosa R, Guerrero N, et al. 2006. Ensayos de variedades de olivo en plantación de alta densidad. Fruticultura Profesional 160:21-6.

Pastor M, Humanes J, Vega V, Castro A. 1998. Diseño y manejo de plantaciones de olivar. Monografías,

22/98. Ed. Consejeria de Agricultura y Pesca. Junta de Andalucía, Sevilla.

Sutter EG. 2005. Olive cultivars and propagation. In: Sibbett GS, Ferguson L (eds.). Olive Production Manual (2nd ed.). UC ANR Pub 3353. Oakland CA p 19-25.

Tous J, Ferguson L. 1997. Olive growing in California. Olivae 67:18-26.

Tous J, Romero A. 2000. 'Arbosana IRTA i-43'. Olint 2:13-5.
J. Tous is Agricultural Engineer, A. Romero is Agricultural Engineer, J. Francisco Hermoso is Agricultural Engineer, and A. Ninot is Agricultural Engineer, Institut de Recerca i Tecnologia Agroalimentaria (IRTA) Mas de Bover research station, Constantí, Catalonia, Spain. We are grateful to the owners of the La Boella farm (La Canonja, Spain) for their collaboration in this trial.
Tous J, Romero A. 2002. Ficha varietal de olivo 'Koroneiki IRTA i-38'. Olint 6:23-5.

Tous J, Romero A, Hermoso JF. 2010. New trends in olive orchard design for continuous mechanical harvesting. Adv Hort Sci 24(1):43-52.

Tous J, Romero A, Plana J. 1999. 'IRTA-i-18', a clone of the 'Arbequina' olive cultivar. Olivae 77(6):50-2. Tous J, Romero A, Plana J. 2003. Plantaciones superintensivas en olivar. Comportamiento de 6 variedades. Agricultura 851(4):346-50.

Tous J, Romero A, Plana J, Hermoso JF. 2008. Olive oil cultivars suitable for very high density planting conditions. Acta Hort 791:403-8.

UC Davis Olive Center. 2009. Survey of Super High Density Olive Production in California. http://olivecenter.ucdavis.edu/files/survey \%20111509\%20revised. pdf.

Vossen PM. 2007. Olive oil: History, production and characteristics of the world's classic oils. HortScience 42(5):1093-100. 


\section{Olive cultivars field-tested in super-high-density system in southern Italy}

\author{
by Angelo Godini, Gaetano Alessandro Vivaldi, \\ and Salvatore Camposeo
}

A ccording to the International Olive Oil Council, world olive oil consumption has risen from 2.8 million tons (1991-1992) to 3.5 million tons (2005-2006), due to increases in the consumption of healthier foods in many countries, including the United States. The market outlook for extra-virgin olive oil is very good, and many countries are actively increasing their olive acreages, particularly in North Africa, the Middle East, South America, Australia and the United States (Godini 2010).

The Mediterranean's traditional olive industry is based on production systems that are hundreds of years old and characterized by low yields and high production costs. The European Union subsidy system, which has helped European olive farmers to stay in busi-

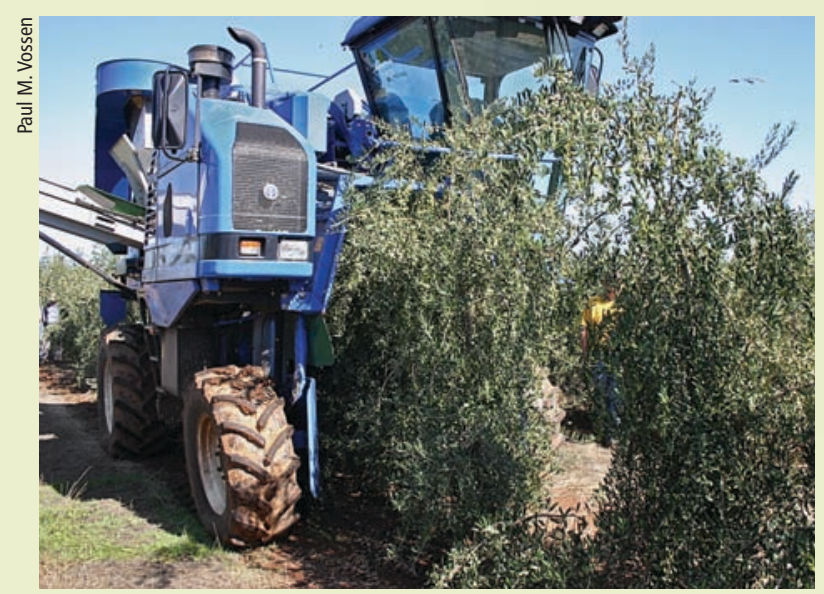

Super-high-density hedgerow planting systems for olives employ over-the-row harvesters (shown, in California).

ness, will end in 2014. Moreover, the application of a "free exchange" area in 2010 will legalize the importation of lower-cost extra-virgin olive oils from the southern Mediterranean Basin into Europe (Godini 2010). Year after year, the profitability of Italy's traditional olive culture becomes increasingly doubtful, notwithstanding the worldwide renown of so-called "Made in Italy" extra-virgin olive oil (Godini and Bellomo 2002).
California production of extra-virgin olive oil is reportedly about $2 \%$ of total U.S. consumption, with the rest imported mainly from Italy and Spain. In recent years, California has started increasing its oil olive acreage. California olive growers have planted more than 22,000 acres since 1999, about 12,000 acres of which is in the super-highdensity olive system, with tree densities of 676 per acre or more. This system allows for mechanical planting and harvesting of olives, reducing labor costs.

We believe that super-high-density olive culture can help to assure profitability for both European and U.S. olive growers in the coming decades. This model, born in Spain at the end of the 20th century, has resulted in noticeable increases in yield per acre. Up until now, super-high-density olive culture has utilized a limited number of cultivars, primarily 'Arbequina', 'Arbosana' and 'Koroneiki', which possess suitable features such as a semidwarf habit, early bearing (first production at the second-to-third year after planting), consistent initial crops (more than 2.2 pounds per plant), crop stabilization between 5 and 6 years, and fruit that is impact-resistant and has good oil quality (Godini and Bellomo 2002).

The results that we present here are preliminary. Considering that Italy's Mediterranean climate is similar to California's, we believe that soil and climate differences should have little influence on the applicability of these findings to California.

\section{Experimental orchard}

In summer 2006, we established a new experimental orchard at Valenzano, near Bari, in the experimental farm of the Dipartimento di Scienze delle Produzioni Vegetali at University Aldo Moro of Bari, Italy. In addition to standard clones of 'Arbequina',
'Arbosana' and 'Koroneiki', two additional cultivars were introduced: 'Coratina', the most popular Apulian olive oil cultivar, and 'Urano', a new Italian cultivar considered by our research group to be well-suited for super-high-density olive culture.

The olive trees were propagated in commercial nurseries by softwood cutting, and the experimental orchard was established according to the super-highdensity planting scheme (676 plant per acre, with a tree spacing of 157.5 inches by 59 inches) and a north-south row orientation. The trees were trained to central leaders. Drip irrigation was supplied to each tree every 3 days between late spring and late summer, increasing from 423 cubic yards per acre annually in 2006, to 476 in 2007, to 794 in 2008 and 2009. Harvesting was performed on Nov. 20 in 2008 and 2009, in the third and fourth years after planting, respectively, using the Pellenc Activ' 4560 harvesting machine.

\section{Cultivar performance}

Vegetation. In December 2009, the average tree height had reached 107 inches, 5.3 times the initial growth of the previous year, with a maximum of 7.6 times more growth for 'Arbequina' and a minimum of 2.2 times more for 'Urano' (table 1). Only the crown width of 'Coratina' exceeded 79 inches by

\begin{tabular}{|c|c|c|c|}
\hline \multirow[b]{2}{*}{ Cultivar } & \multicolumn{2}{|c|}{ Tree height } & \multirow{2}{*}{$\begin{array}{c}\begin{array}{c}\text { Crown } \\
\text { width }\end{array} \\
\begin{array}{c}\text { December } \\
2009\end{array}\end{array}$} \\
\hline & Planting & $\begin{array}{c}\text { December } \\
2009\end{array}$ & \\
\hline & \multicolumn{3}{|c|}{ inches } \\
\hline Arbequina & $14.1 b$ * & 107.3b & $77.5 b$ \\
\hline Arbosana & $13.0 \mathrm{~b}$ & $97.0 \mathrm{c}$ & $77.7 b$ \\
\hline Coratina & $16.9 b$ & $120.9 a$ & $96.5 a$ \\
\hline Koroneiki & $16.0 \mathrm{~b}$ & 117.6a & $78.4 \mathrm{~b}$ \\
\hline Urano & $41.1 \mathrm{a}$ & $92.7 c$ & $74.5 b$ \\
\hline Mean & 20.2 & 107.1 & 80.9 \\
\hline
\end{tabular}

* Within the same column and for a single parameter, different letters mark values significantly different at $P=0.01$ (SNK test) 
December 2009, exceeding the harvester tunnel size and requiring pruning intervention to control its transverse canopy growth.

Annual yields. The average annual yield in the third year was 7.7 pounds per tree, equivalent to 2.3 tons per acre; only 'Urano' exhibited a surprisingly high yield of 3.7 tons per acre (table 2 ). In the fourth year, the average crop yield was 11 pounds per tree or 3.3 tons per acre (up 40\% from 2008), and it was more variable among cultivars. 'Koroneiki', 'Arbosana' and 'Arbequina' followed by 'Coratina' gave satisfactory yield (between 13.7 and 11.3 pounds per tree or 4.1 and 3.4 tons per acre). The yield for 'Urano' dropped to 4.9 pounds per tree or 1.5 tons per acre, perhaps due to heavy cropping in the previous year.

Cumulative yields and oil. We also compared cumulative yields over the first 4 years of the trial. 'Koroneiki' showed the highest cumulative yield (41.3 tons per acre), and 'Urano' was relatively less productive (31.6 tons per acre) (table 2). The peculiar behavior of 'Urano' requires further investigation. Considering its average overall oil content of about $17.0 \%$, 'Koroneiki' was the most productive cultivar with 6.9 tons per acre of oil over 4 years. The other cultivars exhibited similar cumulative oil production.

Harvesting efficiency, fruit and shoot damage. Harvesting efficiency was satisfactory on the whole (93.1\%), notwithstanding differences among cultivars (table 3). 'Arbequina', 'Coratina' and 'Urano' had the highest harvest

TABLE 3. Harvesting efficiency, damaged fruits and damaged shoots per tree, as mean of the third and fourth year after planting

\begin{tabular}{lccc}
\hline Cultivar & $\begin{array}{c}\text { Harvesting } \\
\text { efficiency }\end{array}$ & $\begin{array}{c}\text { Fruit } \\
\text { damaged }\end{array}$ & $\begin{array}{c}\text { Shoots } \\
\text { damaged }\end{array}$ \\
\hline Arbequina & $97.2 \mathrm{a}^{*}$ & $0.0 \mathrm{c}$ & $0.4 \mathrm{~b}$ \\
Arbosana & $87.1 \mathrm{~b}$ & $0.0 \mathrm{c}$ & $0.5 \mathrm{ab}$ \\
Coratina & $97.3 \mathrm{a}$ & $1.5 \mathrm{a}$ & $0.2 \mathrm{c}$ \\
Koroneiki & $87.6 \mathrm{~b}$ & $0.0 \mathrm{c}$ & $0.6 \mathrm{a}$ \\
Urano & $96.0 \mathrm{a}$ & $0.4 \mathrm{~b}$ & $0.2 \mathrm{c}$ \\
Mean & 93.1 & 0.4 & 0.4 \\
\hline
\end{tabular}

*Within the same column and for a single parameter different letters mark values significantly different at $P=0.01$ (SNK test)

TABLE 2. Fruit production per year, cumulative yield at the third (2008) and fourth (2009) year after planting, and mean oil output and cumulative production

\begin{tabular}{|c|c|c|c|c|c|}
\hline \multirow[b]{2}{*}{ Cultivar } & \multicolumn{2}{|c|}{ Fruit production } & \multirow{2}{*}{$\begin{array}{c}\text { Cumulative } \\
\text { yield* }^{*}\end{array}$} & \multirow{2}{*}{$\begin{array}{c}\text { Mean oil } \\
\text { output }\end{array}$} & \multirow{2}{*}{$\begin{array}{c}\text { Cumulative oil } \\
\text { production }\end{array}$} \\
\hline & 3rd year & 4th year & & & \\
\hline & \multicolumn{2}{|c|}{$\ldots \ldots$ pounds/treet $\ldots . .}$. & tons/acre & $\%$ & tons/acre \\
\hline Arbequina & $5.5 b \neq$ & $12.4 a b$ & $33.4 b$ & 17.7 & $5.68 b$ \\
\hline Arbosana & $6.2 b$ & $12.6 a b$ & $35.1 \mathrm{ab}$ & 17.5 & $5.83 b$ \\
\hline Coratina & $7.1 \mathrm{~b}$ & $11.3 b$ & $34.1 b$ & 17.3 & $5.86 \mathrm{~b}$ \\
\hline Koroneiki & $8.4 b$ & $13.7 a$ & $41.3 a$ & 15.0 & $6.89 a$ \\
\hline Urano & $12.1 \mathrm{a}$ & $4.9 c$ & $31.6 c$ & 16.8 & $5.26 b$ \\
\hline Mean & 7.7 & 11.0 & 35.1 & 16.9 & 5.91 \\
\hline
\end{tabular}

* Over four years of the trial.

$\dagger 7.73$ pounds per tree $=2.3$ tons per acre.

$\ddagger$ Within the same column and for a single parameter, different letters mark values significantly different at $P=0.01$ (SNK test).

efficiency; 'Arbosana' and 'Koroneiki' were less satisfactory. But these differences were due to the fruit-ripening stages reached by each cultivar at the harvesting date: mature for 'Arbequina', 'Coratina' and 'Urano', but immature 'Arbosana' and 'Koroneiki'.

No damaged fruits were reported for 'Arbequina', 'Arbosana' and 'Koroneiki', whereas 'Coratina' and 'Urano' exhibited very low percentages of damaged fruit.

The average percentage of shoots damaged per tree by the harvesting machine beaters was insignificant at less than $1.0 \%$. Of these damaged shoots, young and thin current-year shoots incurred the most damage (80.0\%), perhaps because they were more exposed. The percentage of damaged shoots up to 1 inch in diameter was $14.3 \%$, and to shoots thicker than 1 inch was $5.7 \%$. Only 'Coratina' and 'Urano' exhibited a significant percentage of broken shoots or branches thicker than 1 inch: 'Coratina' because of its spreading habit between rows, and 'Urano' because of its spreading habit and thick, bending branches.

\section{High density, high yields}

The present data confirms and improves upon results obtained in previous experimental trials (Camposeo and Godini 2010). In terms of early bearing and yield consistency, all the tested cultivars performed satisfactorily. And in sensory evaluations, the resulting extravirgin oils had sweet typology and were well-balanced, highly fruity and ready to use (Camposeo et al. 2010).
We know that higher yields have been recorded elsewhere with superhigh-density olive culture; however, we consider annual yields of about 17.5 tons per acre of fruit to be satisfactory. In fact, this value, equivalent to a yield of only about 9.4 pounds per tree, would be helpful in avoiding alternate bearing and subsequent problems that could cause conflicts between vegetative growth and cropping consistency. Tree size can be controlled by pruning when they grow larger than the size of the harvester head. Our data indicates that the noted yield limit was reached by at least four out of five cultivars in just the 4 th year after planting.

A. Godini is Professor, G. Allesandro Vivaldi is Ph.D. Student, and S. Camposeo is Ph.D. Researcher, Dipartimento di Scienze delle Produzioni Vegetali, University Aldo Moro of Bari, Italy. The authors wish to thank Provincia di Bari, Italy, for its financial support of this research.

\section{References}

Camposeo S, Ferrara G, Palasciano M, Godini A. 2008. Varietal behaviour according to the superintensive oliveculture training system. Acta Hortic 791:271-4.

Camposeo S, Godini A. 2010. Preliminary results about the performance of 13 cultivars according to the super high density oliveculture training system in Apulia (Southern Italy). Adv Hortic Sci 24(1):16-20.

Camposeo S, Vivaldi GA, Gallotta A, et al. 2010. Valutazione chimica e sensoriale degli oli di alcune varietà di olivo allevate in Puglia con il modello superintensivo. Frutticoltura 72(6):80-83 (in Italian with summary in English).

Godini A. 2010. L'olivicoltura italiana tra valorizzazione e innovazione. Frutticoltura 72(6):52-69 (in Italian with summary in English).

Godini A, Bellomo F. 2002. Olivicoltura superintensiva in Puglia per la raccolta meccanica con vendemmiatrice. International Congress of Oliveculture. Spoleto (Italy), April 22-23:230-4 (in Italian with summary in English). 